\title{
A Cross-Cultural Adaptation and psychometric validation of SISRI-24 among Malaysian Teachers
}

\author{
Kazeem Ogunsola, Assoc. Prof. Fontaine Rodrique \\ and Assoc. Prof. Jan Mohammed
}

\begin{abstract}
The paper is aimed at validating the psychometric properties of SISRI-24 for effective performance among teachers in Malaysia. Through a list-based simple random sampling of 373 teachers, SISRI -24 was translated, adapted and validated. Using TCA procedure, experts validated the translated the instrument from both linguistic structure and semantic point of view. Its internal consistency was validated with Cronbach's Alpha and CFA. EFA varimax normalized rotation extracted four components. Measure of internal consistency had Cronbach's Alpha value of 0.911. CFA validated SISRI-19my with $\chi^{2} / d f$ ratio $(354.512 / 141)=2.514$, RMSEA $(0.077)$ and CFI $(0.921)$ as reasonable spiritual intelligence fit model for Malaysian teachers. The adequacy of this paper's findings is promising, suggesting that the Malaysian version of spiritual Intelligence self-Assessment Inventory scale would provide a valid instrument to develop spiritual intelligence among teachers. Practically, it would stimulate teaching interest irrespective of exigencies. Socially, it models spirited leaders whose role revolves on grooming younger generations towards nation building. Psychological, it acts as catalyst towards improved wellness. Theoretically, it contributes to body of knowledge on spirituality and organizational behaviour. Apart from the study being cross-sectional, it was limited only to private secondary school teachers. Future study may include other strata of teachers to improve SISRI-19my version. The study offers the first to empirically translate, adapt and validate a Malaysian version of SISRI-24.
\end{abstract}

Keywords: Spiritual intelligence (SQ), Spiritual assessment inventory, Psychometric questionnaire validation, Task performance, Teachers, Malaysia.

\section{INTRODUCTION}

Teaching profession is highly charged with responsibilities directed towards not just the students, colleagues or parents, but also towards organizational values, mission and ideas $(1,2)$. In most climes, teachers are the backbone of a successful learning environment $(3,4)$. By implication, teaching is a profession which is seemingly responsible for the future of a society or nation (5). Hence, teachers deserve unparalleled attention with regards to this role.

Given this pivotal role, couple with the challenges of teaching $21^{\text {st }}$ century young generations, teachers needed to develop the quality of both head and heart $(6,7)$. A possible recommendation proposed by researchers is to encourage employees' spirituality (8-11). Extended research in the field of psychology has shown that spirituality tends to promote adaptability, task commitment, , wellness, profitability and personal fulfilment (12). Consequentially, spirited teachers would be represented as a "whole person" at work (13), bringing about a balance between their well-being, perceived responsibilities and achievement of organizational values (14).

As a result of the "intimate and proven interplay" that exist between spirituality and intelligence (15), teachers would expectedly be provided with the skills, abilities and behaviours required to solve adaptive problems and attain goals (e.g., search for the ultimate and personal true values) in everyday lives (16) or imbued with the "strength and self- 
confidence to face adversities in life" (10). Given these benefits, this paper saw it relevant to validate a Malaysia version of the original SISRI-24 for teachers' improved performance and personal wellness.

\section{Teachers}

\section{LITERATURE REVIEW}

There is the increased awareness towards understanding how spirituality will benefit teachers and improve their organizational performance (7). Supposedly, teachers are saddled with multiple roles ranging from being a mentor, colleague, friend, or supervisor. (17) assents that teachers' role includes integration and application of knowledge. Expectedly, such role requires them to be imbued with requisite skills or capability to perform optimally (1). And by extension, to help them keep a balance between their personal and organizational values during service interaction (18).

Studies on human intelligence indicated that spiritual intelligence (SQ) provides a positive link between performance, job satisfaction and commitment (19). More recent findings revealed that people perceived to be high in spiritual intelligence (SQ) are usually able to give symbolic meaning to job activities (20). In other words, they modify a situation in order to reduce or alter its psychological and physiological impact (21). Hence, spiritual intelligence (SQ) might be that requisite skills needed by teachers for optimal performance. Perhaps, they may be able to control their emotions and render selfless service.

Some studies argued that as nation's builders, teachers needed to be nourished (e.g., spiritually) in order to impart quality education, love, sympathy, trust-worthiness, kindness or other kinds of humane (moral) virtues in their subjects $(1,11,22)$. With spiritual nourishment, it is presumed that teachers will be able to inspire younger generation (i.e., future leaders) with true values necessary for integration, tolerance, nobility and so forth (23-25).

It is worth noting that the deficiency of these humane virtues amongst leaders may provide justifications why organizations across the globe still experience corporate crimes. Corporate crimes are "crimes committed either by corporation or individuals acting on behalf of a corporation"(26) The study of (27) found that religious belief is associated with lower level of white-collar crimes. Researchers $(28,29)$ argued that the $21^{\text {st }}$ century leaders need the components of spirituality to revamp the failing society.

To this end, the teaming youths are better trained and educated by teachers instilled with spiritual qualities or capability (e.g., spiritual intelligence) in order to salvage the future from total collapse. Evidences revealed that youths (e.g., students) who are trained with spiritual virtues and practices are less likely to engage in anti-social behaviours. So, aside from teachers' search for meaning and purpose at work through spiritual intelligence, they equally doubled as role model in fostering harmony, progress and development of any nation.

\section{Spiritual intelligence}

In the theory of multiple intelligences, eight form of intelligences were proposed (30) . But later, Gardner argued for "existential intelligence as the domain of human intelligence" responsible for solving problems with spiritual instincts. Existential intelligence being the ninth form of intelligence is presumed to be an autonomous intelligence based on human inclination to ponder the most fundamental questions of existence $(16,31,32)$. In other words, existential intelligence relates the set of skills involving the use of collective values and intuition to understand others and the world around them $(33,34)$. This form of intelligence is perhaps more needed within the current educational system in nurturing new generation of leaders. 
Given this backdrop, spiritual intelligence becomes increasingly being studied among management researchers $(35,36)$. Spiritual intelligence is used to denote intelligence capacity that integrates the functions of IQ (logical and rational reasoning) (19) and EQ (interaction) (18) to achieve superior functions such as maintaining inner balance with life realities (37-39). This suggests that spiritual intelligence "is the central and most fundamental of all intelligences, because it becomes the source of guidance for the others" (40 p. 53). spiritual intelligence as a "form of intelligence which instils a reserved and heightened state of consciousness in an individual to feel, interact and behave with calmness irrespective to environmental (public or private domain) exigencies" (Authors).

In this connection, studies are showing prominent interest on developing teachers' spiritual intelligence. A positive relationship was found between teachers' efficacy and spiritual intelligence (4). Another revealed that spiritual intelligence provides active, unity and meaningful centre for soul to help teachers think and solve both existential and daily problems (41). It was also found out that more can be achieved through spirituality in improving education system (42). Some researchers (43) explained that academic achievements and effectiveness of teachers relates proportionally to their perceived level of spiritual intelligence. Others (44) summed it that spiritual intelligence equips teachers with skills and ability to live with an open heart, hence are able to express innate spiritual qualities (e.g., love, peace or purity) through attitudes, behaviours and thoughts (45).

With the foregoing discussion, it may be important to consider same for Malaysian teachers. This will further kindle the unrelenting effort by Ministry of Education towards improving the education sector. According to the Ministry's guidelines (3), "teachers are expected to have good personality, possess knowledge and skills, foster an improvement in learning and contribute to the nation's development." So, validating a Malaysian version of Spiritual Intelligence Scale may augment the attainment of these set guidelines.

\section{Measure (Instrument)}

\section{METHOD}

The research instrument used was the King and DeCicco (2009) original version of Spiritual Intelligence Self-Report Inventory (SISRI-24). SISRI-24 comes with 24 items on a five-point Likert-type scale of $(0=$ 'not at all true of $m e$ ' and $4=$ 'completely true of $m e$ ') to measure various behaviours, thought processes and mental characteristics of individuals. SISRI-24 is divided into four sub-scales; Critical Existential Thinking (CET - 7 items), Personal Meaning Production (PMP - 5 items), Transcendental Awareness (TA - 7 items) and Conscious State Expansion (CSE - 5 items). All sub-scale items were coded positively except for item SQ14 "It is difficult for me to sense anything other than the physical and material" on Transcendental Awareness (TA) which needed to be reversed prior to summing the scores.

The Original SISRI-24 total scores ranged from 0 -96, with higher scores representing higher levels of spiritual intelligence and/or each capacity. Using a Varimax Normalized rotation, King and DeCicco (2009 p.76) reported a four-factor solution for SISRI-24, Cronbach's Alpha $(\alpha=$ 0.92) suggesting a good scale reliability, internal consistency and excellent psychometric properties. Its confirmatory factor analysis (CFA) revealed $\chi^{2} / d f$ ratio $(464.68 / 246)=1.86(p$ $<.0001)$, CFI (0.934), GFI (0.886) and RMSEA (0.055), indicating a saturated and good fit model. 


\section{Procedure}

To translate, adapt and validate a psychometrically sound Malaysian SISRI-24 version for teachers, the authors followed Translation and Cultural Adaptation (TCA) guidelines (47). The validation process provided by (48) was equally helpful (see Figure 1).

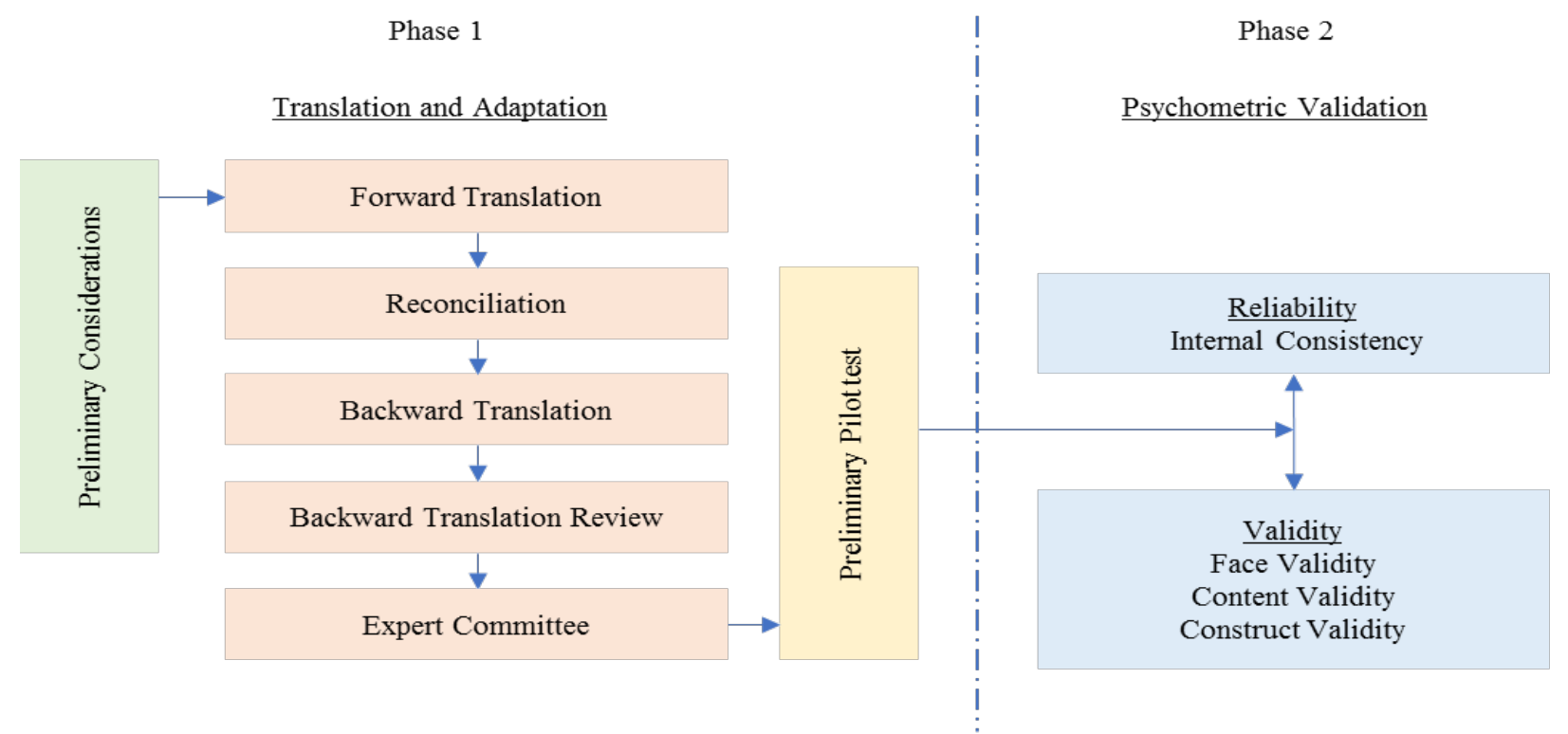

Figure 1: Graphic Representation of Translation, Cross-Cultural Adaptation and Validation (TCAV) Guidelines Source: (Authors' Abridged Version)

The excellency of TCA guidelines has been well demonstrated and proven in existing literatures; E.g., English-Arabic (49), English-Danish (50), English-Chinese (51,52), EnglishKorean (53). Hence, adopting the TCA guidelines may deepen understanding on the uniqueness of Malaysian spiritual world. TCA guidelines come in two phases:

\section{PHASE 1: TRANSLATION AND ADAPTION}

Preliminary Considerations: Before the translation progress began, relevant information on each item in the questionnaire was conceptualized through an experienced in-country consultant who is fluent in English and Bahasa Melayu.

Forward Translation: Two bilingual translators were requested to independently carry out the initial forward translation from source (English) to target (Bahasa Melayu) language. Both are native speakers of Bahasa Melayu. One of the forward translators is an expert and a specialist in Psychology of English and Bahasa language. The other, is though, naïve of the concept being examined, but, an experienced translator with master's degree in Linguistic. Their task was to ensure that the translated version has a degree of similarity with the source (original) questionnaire. Hence, two independent colloquial translations that would be easily understood by the respondents are produced.

Reconciliation: Researchers proposed having a reconciliation panel to resolve discrepancies between the forward translators $(49,54)$. The few identified discrepancies were reconciled to avoid biased or one-person's own personal style of writing (55). More importantly, to ensure that the nuances in Bahasa Melayu were adequately captured. After reconciliation, an agreed translated version was produced, ready to be back-translated.

Backward Translation: Accordingly, back-translator(s) should be professionals, native speakers of the source language and fluent in the target language $(56,57)$. Preferably, they 
should have no prior knowledge of the original instrument $(54,58)$, or any other language version of the instrument to avoid bias (59). In view of this, a naïve bilingual native English speaker was recruited to produce a blind back-translation into English. The outcome of this reversed process indicated that a substantial agreement with the original instrument.

Backward Translation Review: This review was done in conjunction with the in-country person (expert). It was aimed at ensuring that no mistranslation or omission exists, which may jeopardize or may remain permanent in the Malaysian SISRI-24 version.

Expert Committee: The expert committee ensured that the semantic, idiomatic, experiential and conceptual equivalence between the source and target (translated) questionnaire were achieved. To further lend credence to the translated questionnaire, a 12-year-old (roughly a Grade 6 level) pupil was recruited in order to access these equivalences and the understandability of the translated questionnaire. This pre-test is a "general recommendation for newly developed questionnaires" (60 p.3189). The committee reviewed all discrepancies, reached consensus and produced the pre-final version of the translated questionnaire for pilot testing.

Preliminary Pilot Testing: Based on recommendations (61,62), a 'probe technique' (54 p.1424) was adopted to pilot test the pre-final translated questionnaire on 35 participants in order to ascertain its face and content validity. The outcome produced Cronbach's Alpha $(\alpha=$ 0.901). This gave the assurance that a reasonable and effective translation have been conducted. Hence, the original SISRI-24 was adapted and renamed SISRI-24my as the Malaysian version.

\section{PHASE 2: PSYCHOMETRIC VALIDATION OF SISRI-24MY VERSION}

To establish the reliability and construct validity of SISRI-24my, it was administered to the main population.

\section{Main Study Participants}

Participants were teachers working around peninsular Malaysia. Through a list-based simple random sampling technique, 30 schools were randomly selected using research randomizer software. Apart from the initial covering letter, the researchers personally met with the school heads to brief them about the purpose of the study and the procedures for the survey.

\section{Sample Size}

15 teachers were randomly selected from each of the schools. Hence, 450 teachers were expected to respond to the survey questionnaire. This sample is adequate given the minimum threshold of five per item $(48,63,64)$.

\section{Data Collection}

To ensure confidentiality, data were collected electronically through Google forms. It was argued that such means "guaranteed informed consent and data confidentiality" (11 p.5). It also offers the opportunity to respond to the questionnaire at convenience. Moreover, "more reliable data are likely to result since the respondents can go back and forth, and easily change a response" (65 p.250). The data were collected between May and August 2019.

\section{Statistical Analysis}

IBM SPSS 24.0 software was used for demography frequencies and EFA. AMOS 24.0 software was used for CFA data validation. 


\section{Response Rate}

\section{RESULTS}

From 450 expected responses, 35 respondents participated in the pilot study instrument adaptation stage. Main study had 415 participants, out of which 389 responses were received, giving a response rate of 93.74\%. 16 responses were invalidated with respect to recommendations (66). As a result, only a total valid 373 usable responses were finally analysed, giving a usable response rate of $89.88 \%$. The high response rate was due to several follow-up measures (e.g., phone calls, emails, visitations). Besides, prior to beginning the survey, consultations were made with the heads of each school to pre-inform them on the intent of the survey. The convenience of the responding to an electronic questionnaire also contributed to the high response rate.

\section{Social - Demographic Characteristics Report (Main Study)}

Respondents are mostly aged between 30 and 45 years $(M=2.35 ; \mathrm{SD}=1.02)$. With respects of male (Table not shown), 52 (14.0\%) and 167 (44.8\%) females have master's and bachelor's degree respectively, $122(32.7 \%)$ female have spent over 10 years in the teaching profession, while 176 (47.2\%) were married.

The social-demographic table revealed unequal representation of gender as teachers. It can be inferred that there are more female teachers than their male counterpart. This outcome is not confounding given Ministry of Education (2018 p. 26) report which revealed that there are more females than males in the Malaysian education system generally.

\section{Questionnaire Characteristics Report}

The descriptive statistics of SISRI-24my (Table 1) revealed that average response on a scale of ' 0 ' and ' 4 ' was highest for item TA $(M=3.22, S D=0.81)$. The lowest response was on CET $(M=$ $2.99, S D=0.90)$.

Table 1. Average Mean, Standard Deviations and Reliability

\begin{tabular}{ccccc}
\hline Constructs & Alpha & Items & Mean & SD \\
\hline & 0.929 & & & \\
CET & & 7 & 2.99 & 0.90 \\
PMP & & 5 & 3.13 & 0.85 \\
TA & & 7 & 3.22 & 0.81 \\
CSE & 5 & 2.84 & 0.93 \\
\hline Aggregate Average Score & & 24 & $\mathbf{3 . 0 5}$ & $\mathbf{0 . 8 7}$ \\
\hline
\end{tabular}

Source: SPSS Output Table (2019).

Nonetheless, aggregate average mean of SISRI-24my $(M=3.05, S D=0.87)$ reflects that the use spiritual intelligence is very true for majority of teachers. Careful observation of its skewness and kurtosis (not shown) indicated that they fell within acceptable $z$ score range $( \pm 1.96 ; p=$ 0.05). Supporting that data are normally distributed $(64,67)$.

\section{Psychometric validation report:}

Two validation processes: EFA and CFA: were performed..

\section{Exploratory Factor Analysis (EFA)}

EFA was performed to (re)confirm the factorial structure of SISRI-24my. All translated questionnaire items were subjected to principal component analysis (PCA) using orthogonal varimax rotation technique. Prior to performing PCA, the suitability of data for factor analysis was assessed. Inspection of correlation matrix (not displayed here due to space) revealed the presence of coefficients $r \geq 0.3$ (67), correlation matrix determinant value $(R$-matrix > 
0.00001) (64), KMO was 0.890, exceeding the recommended value 0.6 (68), and Bartlett's Test of Sphericity (App. $\chi^{2}=2682.111 ; d f=190 ; p<0.05$ ) reached statistical significance $(69,70$ ), supporting the factorability of the correlation matrix. The adequacy of the data was equally proven with items having communalities values above recommended 0.3 threshold $(11,67)$.

In Table 2, factors were retained based on Kaiser's criterion, Scree plot and "predetermined number of factors based on research objectives and /or prior research" (71 p.122). Factor loading during extraction was pegged at 0.5 to reveal the practical significance of each variable. It was argued that "values greater than \pm 0.50 are generally considered necessary for practical significance" (71 p.219).

Table 2. Rotated Component Matrix ${ }^{a}$

\begin{tabular}{|c|c|c|c|c|c|}
\hline \multirow[b]{2}{*}{ Items } & \multicolumn{4}{|c|}{ Components } & \multirow[t]{2}{*}{ Communality } \\
\hline & $\begin{array}{c}1 \\
\text { CET }\end{array}$ & $\begin{array}{c}2 \\
\text { PMP }\end{array}$ & $\begin{array}{c}3 \\
\text { TA } \\
\end{array}$ & $\begin{array}{c}4 \\
\text { CSE } \\
\end{array}$ & \\
\hline SQ6 & 0.825 & & & & 0.723 \\
\hline SQ4 & 0.727 & & & & 0.603 \\
\hline SQ5 & 0.714 & & & & 0.566 \\
\hline SQ7 & 0.654 & & & & 0.668 \\
\hline SQ3 & 0.648 & & & & 0.596 \\
\hline SQ2 & 0.506 & & & & 0.526 \\
\hline SQ9 & & 0.859 & & & 0.755 \\
\hline SQ11 & & 0.787 & & & 0.735 \\
\hline SQ10 & & 0.753 & & & 0.609 \\
\hline SQ8 & & 0.622 & & & 0.437 \\
\hline SQ12 & & 0.614 & & & 0.600 \\
\hline SQ18 & & & 0.786 & & 0.777 \\
\hline SQ19 & & & 0.757 & & 0.752 \\
\hline SQ15 & & & 0.694 & & 0.685 \\
\hline SQ17 & & & 0.576 & & 0.469 \\
\hline SQ13 & & & 0.520 & & 0.562 \\
\hline SQ20 & & & & 0.812 & 0.670 \\
\hline SQ21 & & & & 0.655 & 0.608 \\
\hline SQ23 & & & & 0.614 & 0.652 \\
\hline SQ22 & & & & 0.568 & 0.612 \\
\hline Sum of Squares & 3.616 & 3.307 & 3.429 & 2.273 & 12.625 \\
\hline Percentage of trace & 18.08 & 16.54 & 17.15 & 11.36 & 63.13 \\
\hline Cronbach's Alpha & 0.843 & 0.830 & 0.837 & 0.785 & \\
\hline \multicolumn{6}{|c|}{ Determinant Value 0.0001 at $(R-$ matrix $>0.00001)$} \\
\hline \multicolumn{6}{|c|}{ Total \% Variance explained $63.13 \%$} \\
\hline \multicolumn{6}{|c|}{ Kaiser-Mayer-Olkin Measure (KMO) 0.890} \\
\hline Bartlett's test of $\mathrm{Sp}$ & ty 0.00 & $<0.05$ & & & \\
\hline
\end{tabular}

Extraction Method: Principal Component Analysis (PCA).

Rotation Method: Varimax with Kaiser Normalization.

a. Rotation converged in 7 iterations.

Four items (SQ1, SQ14, SQ16, SQ24) did not load on any of the factored components. So, a rerun of PCA produced a four-components solution with 20 items. Both Kaiser's criteria and Screeplot (not displayed here due to space) equally supported the four-factor solution. To confirm this, varimax normalized rotation was performed. The rotated component matrix also produced four components with a number of strong loading and all variables loading substantially on each component extracted (Table 2). The naming of the four components was based on existing literature $(11,12,46,72)$. The reliability of the new factored solution was reexamined, Cronbach's alpha revealed $0.816,0.816,0.856$ and 0.741 for CET, PMP, TA and CSE respectively. The overall scale reliability for SISRI-20my is 0.911 (see Table 3). 
Table 3. Reliability Statistics for SISRI-20my

\begin{tabular}{lccc}
\hline & \multirow{2}{*}{ No of items } & \multicolumn{2}{c}{ Cronbach's Alpha $(\alpha)$} \\
\cline { 3 - 4 } Spiritual Intelligence Self-Report Inventory & 6 & Original & Translated \\
\hline Critical Existential Thinking (CET) & 5 & 0.78 & 0.843 \\
Personal Meaning Production (PMP) & 5 & 0.78 & 0.830 \\
Transcendental Awareness (TA) & 4 & 0.87 & 0.837 \\
Conscious State Expansion (CSE) & 20 & 0.91 & 0.785 \\
\hline Overall Reliability Value for Main Study & & 0.911 \\
\hline
\end{tabular}

\section{Source: (Authors' compilation)}

Only CSE was slightly low when compared to the original (source) questionnaire, researchers explained that sometimes "it is not always the case" that the translated questionnaire version has sound construct validity and reliability as the source questionnaire (60 p.3189). Perhaps, due to cultural differences (73) or the uniqueness of a particular population sample (74) which often renders specific item(s) in the source (original) questionnaire difficult to translate. Hence, researchers may experience changes in statistical or psychometric properties of an instrument. Nonetheless, an 0.70 value indicate good scale internal consistency (75). So, in the overall, the translated questionnaire demonstrated good properties to engage in further statistical test $(64,76)$.

\section{Confirmatory Factor Analysis (CFA):}

CFA was carried out to test how well the factored solution represents the sampled population. Maximum Likelihood method was adopted using AMOS 24 software to determine fit indices. Results are as displayed in Table 4.

Table 4. CFA Result for Spiritual Intelligence Self Report Inventory

\begin{tabular}{|c|c|c|c|}
\hline \multirow[b]{2}{*}{ Goodness-of-Fit Statistics } & Default Model & Modified Model & \multirow[b]{2}{*}{ Threshold } \\
\hline & SISRI-20my & SISRI-19my & \\
\hline Chi-Square $\left(\chi^{2}\right) / d f$ & $529.840 / 164$ & $354.521 / 141$ & Sensitive to size \\
\hline \multicolumn{4}{|l|}{ Absolute Fit Measures } \\
\hline P-value & 0.000 & 0.000 & \\
\hline Normed Chi-square (CMIN/DF) & 3.231 & 2.514 & $2>r<5^{*}$ \\
\hline Root Mean Sq. Error of Appr. (RMSEA) & 0.094 & 0.077 & $<0.08^{* *}$ \\
\hline Goodness of Fit Index (GFI) & 0.827 & 0.874 & $>0.90 * * *$ \\
\hline \multicolumn{4}{|l|}{ Incremental Fit Indices } \\
\hline Comparative Fit Index (CFI) & 0.870 & 0.921 & $>0.90 * * *$ \\
\hline Tucker-Lewis Index (TLI) & 0.849 & 0.904 & $>0.90 * * *$ \\
\hline Incremental Fit Index (IFI) & 0.871 & 0.922 & $>0.90 * * *$ \\
\hline
\end{tabular}

\section{Source: AMOS Output Table (2019)}

*Ratios as low or as high as 5 indicate a reasonable fit (77)

**Values of about 0.08 or less would indicate a reasonable fit (78)

**Values closer to 1 indicate a very good fit $(79,80)$

During CFA, item SQ8 was further deleted because it fell below expected loading values. This further reduced the translated scale to 19 items (i.e., SISRI-19my). A four-components 19 items solution provided reasonable fit for a Malaysian version of spiritual intelligence scale with $\chi^{2} /$ $d f$ ratio $(354.512 / 141)=2.514$, RMSEA (0.077) and CFI (0.921). All values are within the stipulated ranges for good model fit. Therefore, SISRI-19my is ideally suitable for Malaysian teachers.

SISRI-19my was further subjected to construct validity test, examined through convergent validity, and discriminate validity. 
Table 5. Reliability and Validity Assessment Tests

\begin{tabular}{lccc}
\hline & Values for SISRI-19my & Threshold & Remarks \\
\cline { 2 - 4 } Construct Reliability (CR) & 0.955 & $\mathrm{CR} \geq 0.70$ & Supported \\
Average Variance Extracted (AVE) & 0.531 & $\mathrm{AVE} \geq 0.50$ & Supported \\
Cronbach Alpha $(\alpha)$ & 0.925 & $\alpha>0.60$ & Supported \\
\hline Convergent Validity & & $\mathrm{CR}>$ AVE & Supported \\
\hline
\end{tabular}

Source: Authors' Computation

In Table 5, CR is 0.95 and AVE is 0.531 . These satisfy the rule of thumb that "average variance extracted (AVE) should equal or exceed 50 percent, with 0.70 as the minimum threshold for construct reliability"(71 p.808). Hence, SISRI-19my demonstrated convergent validity.

Table 6. SISRI-19my Construct Correlation Matric

\begin{tabular}{ccccc}
\hline & CET & PMP & TA & CSE \\
\hline CET & 1 & $0.14^{* *}$ & $0.41^{* *}$ & $0.31^{* *}$ \\
PMP & $0.37^{*}$ & 1 & $0.35^{* *}$ & $0.34^{* *}$ \\
TA & $0.64^{*}$ & $0.59^{*}$ & 1 & $0.45^{* *}$ \\
CSE & $0.56^{*}$ & $0.58^{*}$ & $0.67^{*}$ & 1 \\
\hline Discriminant Validity & \multicolumn{5}{c}{ MSV < AVE } & Supported \\
\hline
\end{tabular}

Significance Level: ${ }^{*} 0.01$ (2-tailed)

**Maximum Shared Variance (MSV)

Note: Values below the diagonal are correlation estimates among constructs, diagonal elements are constructs variances, and values above the diagonal are squared correlations.

In Table 6, AVE (0.531) is greater than the corresponding inter-construct squared correlation estimates (i.e., maximum shared variance - MSV). Thereby, establishing the discriminant validity for SISRI-19my scale. Correlation revealed that all components relate significantly positively to one another $(\mathrm{p}<0.01)$. Taken together, there is support for SISRI-19my construct validity.

\section{DISCUSSION}

In this study, SISRI-24 (46) scale was translated, adapted into Bahasa Melayu and its psychometric properties validated by 373 teachers. This task was carried out in two phases, translation and adaptation phase, and the psychometric validation phase. The translation phase achieved both linguistical and cultural appropriateness $(47,60)$ as was demonstrated through the outcome of the pilot study. Therefore, there were no major concerns following TCA guidelines. This study considers TCA guidelines suitable because it meets "the scientific requirements for translation of instrument dealing with latent phenomena" (50 p.46) such as spiritual intelligence.

Thereafter, the psychometric validation phase employed the aid of different statistical tools to arrive at the most appropriate factorial structure for a Malaysian version of SISRI-24. The outcome revealed that the four components in the original SISRI-24 are equally suitable for a Malaysian version, except for reduction of items in the new scale. This was demonstrated through the use of PCA during EFA. Four factor-solution were extracted consist with the original scale. Though, 20 items were originally extracted as against 24 items proposed by King and DeCicco (46).

The difference between the original scale (SISRI-24) and the translated scale (SISRI-20) might have arisen due to culture or social demography $(73,74)$. For instance, the age range for the original scale was between 17 to 59 years $(M=25.51$; $S D=5.51$ ) and participants were undergraduate psychology students (46 p.73), whereas, the current study had age range between 25 to $55(M=39$; $\mathrm{SD}=6.77)$ with teachers as participants. Working experience as a 
social-demographic characteristic in current study might also be a contributory factor. This, as against the original scale which had students' populace as respondents.

As shown in Table 3, all components, except CSE, displayed higher reliability than those of the original scale. The higher reliability may have been influenced by the religious tenets of the sampled population. A low reliability of CSE component might have been accounted for by teachers' inability to differentiate between goals and idealization. In spite of these differences, extracted factor loading for each sub-scale items were commendable. The highest and lowest EFA values are items SQ6 (0.825) and SQ2 (0.506) on CET sub-scale.

CFA confirmed that SISRI-19my provides a better goodness-of-fit (GOF). Virtually, all its fit indices are better than the default scale (see, Table 4), suggesting the suitability of the modified measurement model for Malaysian teachers. Both convergent and discriminant validity provided good construct validity, such that, all translated sub-scale components have significant correlation with each other.

Taken together, empirical evidence supports a four-structure 19 items (SISRI-19my) in order to develop spiritual intelligence of teachers in Malaysia. Apart from improving their wellness, it may further enhance their role functioning in nurturing younger generation towards nation building. Researcher (81) argued that spiritual intelligent people often show characteristics which include but not limited the following: ability to recognize and use their spiritual values for effectiveness, perform to standard, express enthusiasm, be diligent and so forth.

\section{CONCLUSION}

The current study has successfully translated, adapted and validity the SISRI-19my for Malaysian teachers. It a multi-dimensional scale which seeks to improve the welfare and role functioning of teachers. Spiritual intelligence will aid in navigating the storm of life which might present themselves through psychological or physiological activities. Hence, would facilitate an open and honest relationship with all stakeholders (e.g., students, co-workers, parents or school administrators) to build a successful nation.

\section{LIMITATION AND FUTURE AREAS}

Besides the study being cross-sectional, it is limited by the sampled population. Only private secondary school teachers participated in the survey. Subsequent study may be carried out to see if the study outcome is generalisable to government (public) schools' teachers or other service workers.

\section{References}

1. Letendre GK, Wiseman AW. Introduction: the challenges of teacher effectiveness and quality worldwide. Promot Sustain a Qual Teach Work. 2015;27:1-38.

2. Zembylas M. Caring for teachers emotion: Reflections on teacher self-development. Stud Philos Educ. 2003;22:103-25.

3. Amzat IH, Don Y, Fauzee SO, Hussin F, Raman A. Determining motivators and hygiene factors among excellent teachers in Malaysia: An experience of confirmatory factor analysis. Int J Educ Manag. 2017;31(2):78-97.

4. Marghzar SH, Marzban A. The relationship between spiritual intelligence and efficacy among Iranian EFL teachers. Theory Pract Lang Stud. 2018;8(1):67-73.

5. Kumari M, Chahal D. Spiritual intelligence of secondary school teachers in relation to their demographic variables. Int J Acad Res Dev. 2017;2(4):462-5.

6. Palmer PJ. Teaching with heart and soul: reflections on spirituality in teacher education. J Teach Educ. 2003;54(5):376-85.

7. Yocum RG, Densmore-james S, Staal LA, Pinkie EC, Yocum DAE. Exploring spiritual needs in the Classroom - Implications for educators. Forum on Public Policy [Internet]. 2016; Available from: https://files.eric.ed.gov/fulltext/EJ1126343.pdf

8. Osman-Gani AM, Hashim J, Ismail Y. Establishing linkages between religiosity and spirituality on employee performance. Empl Relations [Internet]. 2013;35(4):360-76. Available from: http://www.emeraldinsight.com/doi/10.1108/ER-04-2012-0030

9. Khaliq A, Ogunsola OK. An empirical assessment of Islamic leadership principles. Int J Commer Manag. 2011;21(3):291-318. 
10. Bhatti OK, Alam MA, Hassan A, Sulaiman M. Islamic spirituality and social responsibility in curtailing the workplace deviance. Humanomics [Internet]. 2016;32(4):405-17. Available from: http://www.emeraldinsight.com/doi/10.1108/H-03-2016-0022

11. Antunes RR, Silva AP, Oliveira J. Spiritual Intelligence Self-Assessment Inventory: Psychometric properties of the Portuguese version of SISRI-24. J Relig Spiritual Aging [Internet]. 2017;30(1):12-24. Available from: https://doi.org/10.1080/15528030.2017.1324350

12. Fontaine R. Developing spiritual intelligence: Some new evidence. Int J Islam Manag Bus. 2018;7(1):95-107.

13. Milliman J, Bradley-geist JC. The implications of workplace spirituality for person - environment fit theory. Psycholog Relig Spiritual. 2017;9(1):1-12.

14. Mahmood A, Arshad MA, Ahmed A, Akhtar S, Khan S. Spiritual intelligence research within human resource development: A thematic review. Manag Res Rev. 2018;41(8):987-1006.

15. Emmons RA. Is spirituality an intelligence? motivation, cognition, and the psychology of ultimate concern. Int J Psychol Relig. 2000;10(1):3-26.

16. King DB. Rethinking claims of spiritual intelligence: A definition, model and measure. Unpublished Master's Thesis. Trent University, Peterborough, Ontario, Canada; 2008.

17. Kulshrestha S, Singhal TK. Impact of spiritual intelligence on performance and job satisfaction: A study on school teachers. Int J Hum Resour Ind Res. 2017;4(2):1-6.

18. Anwar MA, Osman-Gani AM, Fontaine R, Rahman MS. Assessing organizational citizenship behaviour through constructing emotional intelligence. Asia-Pacific J Bus Adm. 2017;9(2):105-17.

19. Upadhyay S. Can spiritual intelligence influence research performance in higher education? Framework for human resource development in higher education. Adm si Manag Public. 2017;28:153-73.

20. Rani F, Chahal D. Teacher effectiveness in relation to spiritual intelligence of governmental and public school teachers. Sch Res J Humanit Sci English Lang. 2017;4(22):5317-25.

21. Gross JJ. The emerging field of emotion regulation: an integrative review. Rev Gen Psychol. 1998;2(3):271-99.

22. Klerk-luttig J De. Spirituality in the workplace: a reality for South African teachers? South African J Educ. 2008;28:505-17.

23. Fontaine R, Khaliq A, Oziev G. Islamic leadership today. Kuala Lumpur: ICIFE, IIUM; 2017.

24. Khaliq A. Organizational leadership and Succession practices for spirited executives. Malaysian Manag Rev. 2018;53(1):39-54.

25. Ogunsola KO. Servant leadership: Developing an Islamic performance appraisal instrument for Muslim managers. Malaysian Manag Rev. 2018;53(1):55-76.

26. Omar N, Said R, Johari ZA. Corporate crimes in Malaysia: A profile analysis. J Financ Crime. 2016;23(2):257-72.

27. Kaite CE, Blaine R, David P. Religion and the Acceptability of White-Collar Crime : A Cross-National Analysis. J Sci Study Relig. 2012;51(3):542-67.

28. Sarif SM. Tawhidic paradigm and organizational policy and strategy practices. South East Asia J Contemp Business, Econ Law. 2014;5(2):28-35.

29. Fry LW, Latham JR, Clinebell SK, Krahnke K. Spiritual leadership as a model for performance excellence: A study of Baldrige award recipients. J Manag Spiritual Relig. 2016;6086(July):1-27.

30. Gardner H. Frames of mind: The theory of multiple intelligences. New York, NY: Basic Books; 1983.

31. Vaughan F. What is spiritual intelligence? J Humanist Psychol. 2002;42(2):16-33.

32. Grandey AA, Tam AP, Brauburger AL. Affective states and traits in the workplace: diary and survey data from young workers. Motiv Emot. 2002;26(1):31-55.

33. Nasel DD. Spiritual orientation in relation to spiritual intelligence: A consideration of traditional Christianity and New Age/individualistic spirituality. Unpublished doctoral dissertation, University of South Australia; 2004.

34. Noble KD. Spiritual intelligence: A new frame of mind. Spiritual Gift. 2000;9:1-29.

35. Munawar K, Tariq 0. Exploring relationship between spiritual intelligence, religiosity and life satisfaction among elderly Pakistani Muslims. J Relig Health. 2017;57(3):781-95.

36. Wigglesworth C. Why spiritual intelligence is essential to mature leadership. Integr Leadersh Rev [Internet]. 2006;6(3). Available from: http://integralleadershipreview.com/5502-feature-article-why-spiritual-intelligence-is-essential-to-mature-leadership/

37. Mamman A, Zakaria HB. Spirituality and Ubuntu as the foundation for building African institutions, organizations and leaders. J Manag Spiritual Relig. 2016;13(3):246-65.

38. Ramachandaran SD, Krauss SE, Hamzah A, Idris K. Effectiveness of the use of spiritual intlligence in women academic leadership practice. Int J Educ Manag. 2017;31(2).

39. Zohar D, Marshall I. SQ-Spiritual Intelligence: The ultimate intelligence. London: Bloomsbury Publishing; 2000.

40. Covey S. The 8th Habit: From Effectiveness to Greatness. Simon and Schuster; 2004.

41. Ghosh S. Status of workplace spiritual intelligence among secondary school teachers. Int J Sci Res. 2018;7(8):77-86.

42. Wright SP, Horn SP, Sanders WL. Teacher and classroom context effects on student achievement: Implications for Teacher Evaluation. J Pers Eval Educ. 1997;11:57-67. 
43. Rachel GM, Salini V. Spiritual intelligence, its correlation with teacher effectiveness and academic achievement - A study. Int J Educ Psychol Res. 2013;2(2):106-10.

44. Bansal P. Developing spiritual intelligence: contemporary practices in teacher education. Panjab University Sponsored National Seminar on Spiritual Intelligence/ Dev Samaj College of Education,Sec 36, Chandigarh; 2012.

45. Awais M, Malik MS, Qaisar A. A review: The job satisfaction act as mediator between spiritual intelligence and organizational commitment. Int Rev Manag Mark. 2015;5(4):203-10.

46. King DB, DeCicco TL. A Viable model and self-report measure of spiritual intelligence. Int J Transpers Stud. 2009;28(1):68-85.

47. Wild D, Grove A, Martin M, Eremenco S, Mcelroy S, Verjee-lorenz A, et al. Principles of good practice for the translation and cultural adaptation process for patient-reported outcomes (PRO) measures: Report of the ISPOR task force for translation and cultural adaptation. Value Heal. 2005;8(2):94-104.

48. Tsang S, Royse CF, Terkawi AS. Guidelines for developing, transalting, and validating a questionnaire in perioperative and pain medicine. Saudi Jounal Anaesth. 2017;11(1):1-15.

49. Siddiqui KS, Abu-Riash M, Al-Suliman A. Translation and adaptation of English language questionnaire into Arabic for implementation of a large survey on assessing the symptoms of bleeding disorders in Saudi Arabia. J Appl Hemato. 2017;8:156-8.

50. Hertel-Joergensen M, Abrahamsen C, Jensen C. Translation, adaptation and psychometric validation of the good perioperative nursing care scale (GPNCS ) with surgical patients in perioperative care. Int J Orthop Trauma Nurs [Internet]. 2018;29:41-8. Available from: https://doi.org/10.1016/j.ijotn.2018.03.001

51. Chan AWY, Siu AFY. Application of the spiritual intelligence self-report inventory (SISRI-24) among Hong Kong university students. Int J Transpers Stud. 2016;1(1):1-12.

52. Chen Z, Sun H, Lam W, Hu Q, Huo Y, Zhong JA. Chinese hotel employees in the smiling masks : roles of job satisfaction , burnout, and supervisory support in relationships between emotional labor and performance. Int J Hum Resour Manag. 2012;23(4):826-45.

53. Ko J, Price JL, Mueller CW. Assessment of Meyer and Allen's three-component model of organizational commitment in South Korea. J Appl Psychol. 1997;82(6):961-73.

54. Guillemin F, Bombardier C, Beaton D. CROSS-cultural Adaptation of Health-related quality of life measures: Literature review and proposed guidelines. J Clio itpidemiol. 1993;46(12):1417-32.

55. Beaton D, Bombardier C, Guillemin F, Ferraz MB. Recommendations for the cross-cultural adaptation of the DASH \& QuickDASH outcome measures. Inst Work Heal. 2007;June:1-45.

56. Brislin RW, Lonner WJ, Thorndike RM. Cross-cultural research methods. New York: Wiley; 1973.

57. Al-Sayah F, Ishaque S, Lau D, Johnson JA. Health related quality of life measures in Arabic speaking populations: A systematic review on cross-cultural adaptation and measurement properties. Qual Life Res. 2013;22:213-29.

58. Althof SE, Rosen RC, Revicki DA. Linguistic and cultural validation of patient-reported outcomes used in clinical trials. J Sex Med [Internet]. 2018;15(2):115-7. Available from: https://doi.org/10.1016/j.jsxm.2017.11.017

59. Ortiz-Gutiérrez S, Cruz-Avelar A. Translation and cross-cultural adaptation of health assessment tools. Actas Dermo-Sifiliográficas (English Ed [Internet]. 2018;109(3):202-6. Available from: http://dx.doi.org/10.1016/j.adengl.2018.02.003

60. Beaton D, Bombardier C, Guillemin F, Ferraz MB. Guidelines for the process of cross-cultural adaptation of self-report measures Spine (Phila Pa 1976). 2000;25(24):3186-91.

61. Hassan Z. Doing a pilot study: why is it essential? Malaysian Fam Physician. 2006;1(2 \& 3):70-3.

62. Perneger T V, Courvoisier DS, Hudelson PM, Gayet-Ageron A. Sample size for pre-tests of questionnaires. Qual Life Res. 2015;24(1):147-51

63. Frost MH, Reeve BB, Liepa AM, Stauffer JW, Hays RD, Mayo FPMC. What is sufficient evidence for the reliability and validity of patient-reported outcome measures? Value Heal. 2007;10(Supplement 2):94-105.

64. Hair JF (Jr)., Black WC, Babin BJ, Anderson RE. Multivariate data analysis. 7th ed. New Jersey: Prentice Hall.; 2010.

65. Sekaran U. Research methods for business: a skill building approach. 4th ed. John Wiley \& Sons, Inc.; 2003.

66. Ron DH, Honghu L, Arie K. Use of internet panels to conduct surveys. Behav Res. 2015;47(July):685-90.

67. Pallant J. SPSS survival manual: A step-by-step guide to data analysis using SPSS for Windows (version 15). 3rd ed. Australia, Allen \& Unwin; 2007.

68. Kaiser HF. An index of factorial simplicity. Psychometrika. 1974;39(1):31-6.

69. Bartlett MS. A Note on the multiplying factors for various Chi Square approximations. J R Stat Soc. 1954;16:296-8.

70. Tabachnick BG, Fidell LS. Using multivariate statistics. 5th ed. Boston: Pearson Education; 2007.

71. Hair JF (Jr)., Black WC, Babin BJ, Anderson RE, Tatham RL. Multivariate data analysis. 6th ed. New Jersey: Prentice Hall; 2006.

72. Osman-Gani AM, Hassan Z. Impact of spiritual and cultural intelligence on leadership effectiveness: a conceptual analysis. J Islam Manag Stud. 2018;2(1):12-23.

73. Bjorner JB, Kreiner S, Ware JE, Damsgaard MT, Bech P. Differential item functioning in the Danish translation of the SF-36. J Clin Epidemiol. 1998;51(11):1189-202.

74. Wilkinson L. Statistical methods in psychology journals: Guidelines and explanations. Am Psychol. 1999;54(8):594-604.

75. Nunnally JC. Psychometric theory. New York: McGraw-Hill; 1978. 
Ogunsola, K., Rodrique, F., \& Mohammad, J. (2019). A Cross-Cultural Adaptation and psychometric validation of SISRI-24 among Malaysian Teachers. Advances in Social Sciences Research Journal, 6(10) 340-352.

76. Cronbach LJ. Coefficient alpha and the internal structure of tests. Psychometrika. 1951;16(3):297-334.

77. Marsh HW, Hocevar D. Application of confirmatory factor analysis to the study of self-concept: First- and higher order factor models and their invariance across groups. Psychol Bull. 1985;97(3):562-82.

78. Browne MW, Cudeck R. Alternative ways of accessing model fit. In: Bollen KA, Long JS, editors. Testing structural equation models. Newbury Park, CA: Sage; 1993. p. 136-62.

79. Bentler PM. Simultaneous equation sysyems as momnet structure models - With an Introduction to Latent Variable Models. J Econom. 1983;22:13-42.

80. Zainudin A. A handbook on SEM for academicians and practitioners. The step by step practical guides for the beginners. Selangor: MPWS Rich Resources; 2014.

81. Lynton N, Thøgersen KH. Spiritual intelligence and leadership in the China laboratory. J Int Bus Ethics. 2009;2(1):112-8. 